International Review of Research in Open and Distributed Learning Volume 19, Number 1

February - 2018

\title{
How Learners Participate in Connectivist Learning: An Analysis of the Interaction Traces From a cMOOC
}

\author{
Zhijun Wang ${ }^{1}$, Terry Anderson ${ }^{2}$, and Li Chen ${ }^{3}$ \\ ${ }^{1}$ Jiangnan University, China, ${ }^{2}$ Athabasca University, Canada, ${ }^{3}$ Beijing Normal University, China
}

\begin{abstract}
In this research paper, the authors analyse the collected data output during a 36 week cMOOC. Six-week data streams from blogs, Twitter, a Facebook group, and video conferences were tracked from the daily newsletter and the MOOCs' hashtag (\#Change 11). This data was analysed using content analysis and social network analysis within an interpretative research paradigm. The content analysis was used to examine the technology learners used to support their learning while the social network analysis focused on the participant in different spaces and their participation patterns in connectivist learning.

The findings from this research include: 1) A variety of technologies were used by learners to support their learning in this course; 2) Four types of participation patterns were reveled, including unconnected floaters, connected lurkers, connected participants, and active contributors. The participation of learners displays the participation inequality typical of social media, but the ratio of active contributors is much higher than xMOOCs; 3) There were five basic structures of social networks formed in the learning; and 4) The interaction around topics and topic generation supports the idea of learning as network creation after the analysis of participation patterns that are based on some deep interactive topic. The aim of this study is to gain insight into the behaviors of learners in a cMOOC in an open and distributed online environment, so that future MOOCs designers and facilitators can understand, design and facilitate more effective MOOCs for learners.
\end{abstract}

Keywords: participation pattern, cMOOCs, social network analysis, connectivist learning, connectivism, interaction 


\section{Introduction}

MOOCs have attracted worldwide research and practice attention from a variety of entities including government, university, enterprise, and other stakeholders (Riel \& Lawless, 2017). Downes (2012a) classified MOOCs into those based on transmission of information (xMOOCs) as differentiated from cMOOCs in which participants collaboratively discover and generate new knowledge. The developments since the first $\mathrm{x}$ and $\mathrm{c}$ MOOCs were first introduced more than 10 years ago, have witnessed the continuing growth of xMOOCs offered by institutions and both for-profit and non-profit companies. The xMOOC model is now much more familiar to learners and teachers in that they often use systems developed for more traditional online courses and use a predominance of micro video lessons and machine marked quizzes for student feedback. xMOOCs have been criticized as not providing sufficient learner support and engagement, however, they have shown capacity of scale, and over their evolution, have added a variety of more novel assessment activities and learning activities including games and simulations (Hew, 2016). cMOOCs have been much less popular, though proponents continue to note that they provide much greater opportunity for student agency, network literacy development and collaborative learning opportunities. Critics of cMOOCs have noted that students encounter "difficulties in way-finding and sense-making because of their lack of necessary knowledge and skills" (Li, Tang, \& Zhang, 2016, p.3) and also often suffer from information overload and unfamiliarity with the learning model being used by instructors that is exacerbated by the information flow from many sources that characterize cMOOCs. As a response to these criticisms, some researchers have been incorporating elements from both types of MOOCs in course design, creating hybrid models (Ostashewski, Howell, \& Dron, 2016; Siemens, 2014; Crosslin \& Dellinger, 2015). Fidalgo-Blanco, Sein-Echaluce, and García-Peñalvo (2016) combined the use of a number of social networks with a single xMOOC platform and found higher course completion rates and learner satisfaction using this hybrid model. If we are to build complete cMOOCs using distributed technologies or add social networking tools to more traditional xMOOCs we need to understand the types of tools chosen by users and the network structures that emerge when using these tools.

Siemens states that learning is a process of connection and network formulation (Siemens, 2005b). These networks include neural networks, concept networks, and external/social networks. Obviously the study of neural networks is far beyond the expectations of this research. However, here we examine how learners' participation in a cMOOC is distributed across learning environments from the social network and concept network perspectives. Because connectivist learning is often supported by various distributed technologies, the research questions are therefore: 1) What kind of technologies do learners use to support their learning? and 2) What kind of participation pattern and network structures are formed among participants and topic during their learning based on learners behavior? Fournier and colleagues (2014) noted that cMOOCs have large, incomplete, and dispersed data sets, so research of participation in cMOOCs is challenging due to the complex and distributed characteristics of this kind of learning. This research intends to help us have a deeper understand of the participation pattern of learners from different perspective with empirical data generated in a cMOOC. We believe that the exploration of learners' participation patterns in cMOOCs will be helpful for future MOOC designers (either cMOOCs, xMOOCs, or hybrids). 


\section{Related Work}

\section{The Development and Innovation of cMOOCs}

Pioneers of Connectivism, George Siemens, Stephen Downes, and other connectivist learning researchers developed and ran a series of Massive Open Online Courses to put their idea of Connectivism into practice from 2008, such as CCo8, CCK10, CCK11, Change 11 MOOC, Openness in Education, etmooc, REL2014, Rhizo15, etc. Among these courses, the Change 11 MOOC had the longest duration and lasted for one and a half years. At that time, MOOCs were known throughout the whole world for the very successful MIT xMOOC course Artificial Intelligence. Thus, Change 11 MOOCs occurred not only at the initial peak of cMOOC development, it was also casually referred to as "the mother of MOOCs" (Siemens, 2011a). MOOCs have since been developing for 10 years. Though many other kinds of MOOCs were proposed and developed, such as SMOOC, MOOR, SPOC, etc., the two main types of MOOCs are cMOOCs and xMOOCs, and the design pedagogies have remained with significant differences (Daniel, 2012; Wang, Chen, \& Zhen, 2014). As Siemens noted, "the cMOOC emphasizes creation, creativity, autonomy and social networking learning, so it focus on knowledge creation and generation, whereas xMOOCs emphasizes a more traditional learning approach through video presentations and short quizzes and testing, so it focus on knowledge duplication" (Siemens, 2012, para. 3). MOOCs have been discussed and researched extensively in the field over the past five years (Riel \& Lawless, 2017). Though there are some innovations of xMOOCs compare with those in 2012 with a linear instructor-led approach, such as designed peer assessment, team-based learning, and social interaction activates in the course, there are some innovations of cMOOCs, or especially Change 11 MOOC that these xMOOCs did not have.

Learning and interactions in cMOOCs are distributed and multi-spaced (Siemens, 2013) as compared with traditional courses offered either in classrooms or online. Learners are able to, and encouraged to, control and shape their learning experiences in cMOOCs - even to the extent of collaboratively defining the curriculum. The design pedagogies and learning objects used and created are based upon learner input and participation. In an $\mathrm{xMOOC}$, the learning interactions take place primarily on a course page or single LMS type system. In a cMOOC, contributions occur and emerge in many distributed online spaces, including blogs, Twitter, Facebook, Wikis, Google Groups, Second Life, YouTube, and dozens of others adopted by learners (Wang, Anderson, Chen, \& Barbera, 2017). Learners joining cMOOCs should be self-directed with high network literacy and autonomy to learning successfully, and they also should be network-directed learners (Siemens, 2011b; Downes, 2011a) to help them create a personal learning environment and collaborative learning environment for the whole participants - if not they can feel overwhelmed in such a complex learning environment. What is more important, they should be knowledge discoverers and creators in the learning process.

So, we argue that more attention should be focused on cMOOCs and their exploration of interaction and network creation centered on learner-learner interaction and on learners' networked knowledge creation and growth (Downes, 2012b; Siemens, 2011c). Learning analytics is used under both MOOC models and is designed to reduce "big data" largely obtained from traces of learner activities into meaningful analysis (Merceron, Blikstein, \& Siemens, 2016). A key research issue is how to gather and analyse critical behavior data in the information flow of a learning activity and how to analyse and interpret individual learning 
behavior characteristics. This study explores and analyses participation patterns based on the interactive behavior traces left across the internet.

\section{cMOOCs Participation}

Researchers and learners interested in Connectivism and the emergent MOOC phenomena joined in the learning of these cMOOCs as participants. A variety of research studies have emerged from this landmark series of cMOOCs. These include the following perspectives: the delivery model innovation introduction of a cMOOC (Fini, 2009; Rodriguez, 2013); Personal Learning Environment design and development with distributed technologies (Kop, 2010; Fournier, Kop, \& Durand, 2014); learners participation and learning experience (Saadatmand \& Kumpulainen, 2014; Smith \& Eng, 2013; Levy, 2011; Kop, 2011; Mackness, Mak, \& Williams, 2010), and a focus on facilitators' experiences (Arnold, Kumar, Thillosen, \& Ebner, 2014). Some studies (Siemens, 2011c; Milligan, Littlejohn, \& Margaryan, 2013, 2013; Skrypnyk, Joksimović, Kovanović, Gašević, \& Dawson, 2015; Bozkurt et al., 2016, Wang et al., 2017) relate directly to the pattern of interaction and communication observed in these connectivist learning environments. However, in Milligan and his colleagues 's research, the number of participants interviewed is limited compared with the massive number of learners enrolled in the course. What is more important is that these studies divided participant in cMOOCs into three patterns: active participation, passive participation, and lurking. These three types of learners have been identified in online community and distance and online learning for a long time. However, the number of passive learners did not fully match with the educational goal of connection building and collaborative knowledge creation and generation (Siemens, 2013) espoused in connectivist learning. Siemens' research focused on the orientation in complex online learning environments and analysed only the data generated in a single CCK 08 forum, which was only a small part of all data generated in the course. Skrypnyk and colleagues (2015) conducted a social network analysis of Twitter-based course interactions in a cMOOCs to explore the roles of course facilitators, learners, and technology in the flow of information. This study deeply analysis the socio-technical network of human participants and hashtags, and represented the technological affordances for scaling course communication (Skrypnyk et al., 2015, p. 188). Bozkurt and colleagues (2016) analysed interactions, community formation, and nomadic learner behavior in Twitter for a six-week long MOOC within a social network and Community of Inquiry framework. These studies have shown us how learners participate in cMOOCs from the information flow and community formulation perspectives; however, just as the author reported in their study, their limitation was that they only focused on the interaction in Twitter (Skrypnyk et al., 2015; Bozkurt et al., 2016). Though Twitter is one of the main media adopted by most participants, the cMOOC was also supported by the course website, blog, Facebook, and many other technologies. The deepest interaction occurred in the distributed blog websites and these data cannot be ignored (Wang et al., 2017). In earlier work, using deductive analysis of qualitative data, we developed a framework for cMOOC analysis, which we called the Interaction and Cognitive Framework (ICF) (Wang, Chen, \& Anderson, 2014; Wang \& Chen, 2015). The main patterns in four levels of connectivist learning interactions were recognized and described in this work (Wang et al., 2017) with a whole- and macro-perspective analytic lens by qualitative study; however, connectivists argue that learning is a connection-building and network-forming process (Siemens, 2005a, 2005b), We have focused this study on research from a network-building perspective. As Fournier and colleagues (2014) stated, cMOOCs have large, incomplete, and dispersed data sets. This presents many challenges to researchers. This study was conducted with an interpretivist research paradigm, and attempts 
to collect as much data as possible in a distributed, multi-technology supported environment to identify how learners participate in their learning during cMOOC courses.

\section{Methodology}

\section{Course Selection}

As mentioned above, researchers have organized dozens of cMOOCs in the past 10 years. This study selected the Change 11 MOOC as a case because it was referred as the "Mother of all MOOCs" by some participants and can be viewed as a defining model of cMOOCs implementation. This course was the fourth courses developed by these MOOC pioneers and thus benefitted from their earlier experience organization with cMOOCs. This course was co-facilitated by Dave Cormier, George Siemens, and Stephen Downes, and lasted from September 10, 2011 to May 28, 2012 (36 weeks). It was designed to introduce and discuss the changes happening, and projected changes that will occur, within formal education. Each week an invited expert facilitated a live session using with synchronous technology and recorded for an asynchronous presentation and review at a later time. Participants were encouraged to reflect, interact, and undertake knowledge creation, based upon the topics generated by this session and the comments and views of other participants, including the facilitators.

\section{Data Collection and Analysis}

Unlike most xMOOCs, and blog or wiki based cMOOCs, the interaction and learning data in Change 11 MOOCs was distributed across different Web 2.0 technologies and digital platforms. The hashtag \#change11 was defined by course facilitators and used by most participant. Much of the participants' contributions were discovered using the hashtag and was collected and distributed by a tool called gRRShopper (See Figure 1). This content was aggregated into a daily newsletter and was sent to all participants by email, RSS, and archived on a course website.

This study collected data from the daily newsletter in gRRShopper post and followed the \#change11 hashtag to track the interaction the learning flows distributed across the network. This course lasted 36 weeks and more than 2000 people interacted in many different spaces, thus it was impossible to comprehensively analyse all data generated in the course (Wang et al., 2017). An analysis of the number of topics generated in the main spaces showed that week one to week six were the most active portion of the cMOOC and thus this was selected as the focus of our data analysis. 


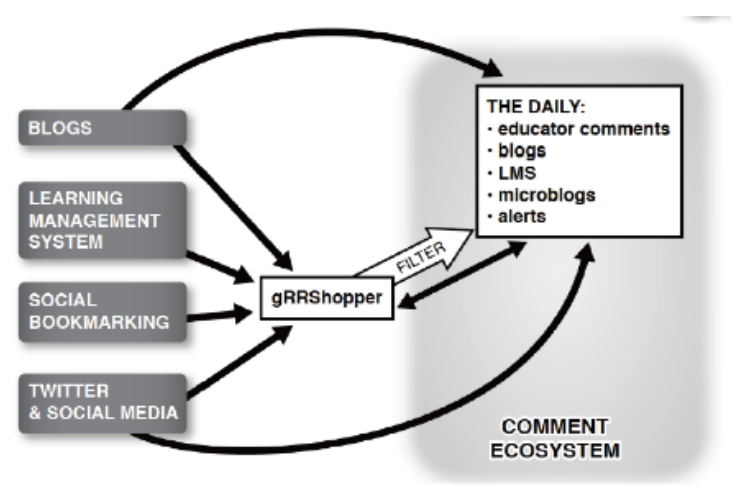

Figure 1. Structure of daily newsletter.

To ensure that all data was collected consistently in the same space, different data collecting rules were defined. We made a detailed introduction to our data collection strategies in our former study Wang et al., 2017). In summary, we itemized the different technologies used for participation and if the technology was used by other participants. These technologies were aggregated to explore the full technology network of the course.

For the learners, as well as the researcher, the distribution of interaction across multi-online learning environments, supported by various technologies, using different usernames, and distributed databases, made it challenging to combine these feeds, produce meaningful learning, and research information. Thus, this study uses social network analysis as the main research methodology. From our earlier work we found learners participate on blogs and Twitter most often but they also joined in an assortment of synchronous and asynchronous learning groups created by both other learners and the facilitators. Given the greater accessibility of the blog (daily newsletter based) this and Twitter (with hashtag\# change11) were chosen as data sources for this study. NodeXL, an open-source social network analysis tool (Bonsignore et al., 2009), that was used for the social network analysis in this study.

Learner behavior in such heterogeneous learning environment(s) supported by different technologies, varies in format, content, and intensity. The coding and analysis rules in the network analysis depended upon the learning behavior supported by a specific technology. For example, the blog based daily newsletter, served content from many online tools designed by different companies and using different formats. Some blog posts included data about the number of shares, likes, and comments posted by readers. However, they did not reveal the identity of these responders nor if they were also enrolled in the MOOC or not. In an attempt to arrive at consistent and valid of data, I ignored this data and used only common features of all blog posts, such as post, reply, and linked by others blog. The final social network coding rules are as follow:

- If participant A posted a new blog post, this was defined as an interaction of this participant to all people in the MOOC and distributed both from the original site and in the daily course newsletter. We defined a role "all" to statistics of original new postings. The code was A to all.

- If B replied to A's posting, the coding is B to A .However, if B forwarded the response using @D in the reply post the coding was $\mathrm{B}$ to $\mathrm{D}$. 
- If $\mathrm{C}$ made a reply to B's replying posting, the coding is $\mathrm{C}$ to $\mathrm{B}$.

Since the structure of blog are different, we used manual coding in the study. The data were checked and revised by manual and NodeXL to assure the validity.

There was a total of 6030 interaction data (including post and comments) nodes in for social network analysis, showing as table 1 .

Table 1

Interaction Data (Posts and Comments) of Each Week in Different Spaces

$\begin{array}{llll} & \text { Blog } & \text { Twitter } & \text { Facebook group } \\ \text { Week 1 } & 311 & 664 & 509 \\ \text { Week 2 } & 462 & 559 & 293 \\ \text { Week 3 } & 390 & 440 & 211 \\ \text { Week 4 } & 404 & 407 & 178 \\ \text { Week 5 } & 181 & 280 & 51 \\ \text { Week 6 } & 459 & 231 & 126 \\ \text { Total } & 2207 & 2581 & 1242\end{array}$

\section{Finding}

This study analysed how learners participate in the cMOOCs from the four different aspects: (1) the technology learners adopted to support their learning; (2) the participation categories formed in the course; (3) the social network structure formed in the different digital spaces; and (4) typical participation patterns based on deep interactive topic.

\section{Technologies Adopted by Learners to Support Their Learning}

In our previous study, we found that learners must first learn how to use different social network technologies to establish and maintain their personal network environment (Wang et al., 2017). Thus, this study identifies which kinds of technologies learners used to support their learning to deepen our understanding of the learning technology challenges to be expected by learners and teachers.

Though course facilitators only officially supported the course website email and Twitter at the beginning of the course, after a week's learning, a variety of technologies were adopted and distributed by participants. These technologies including: 1) video present technology (YouTube, Blip, tumblr); 2) blog technology (wordpress, blogspot, edublogs, saadatm); 3) source aggregation and sharing technology, abbreviated as SAS (Google+RSS, typepad, Scoop it); 4) wiki (wikitionary, wikispace); and 5) other technologies as Google Docs, email, and personal web sites. Besides the technologies above, learners spontaneously built several group spaces for their learning, such as a Facebook group, Diggo group, Open study group, and Google group. As the course proceeded, additional technologies were trialed and/or adopted. The final technology map of six week is visualized in Figure 2. 


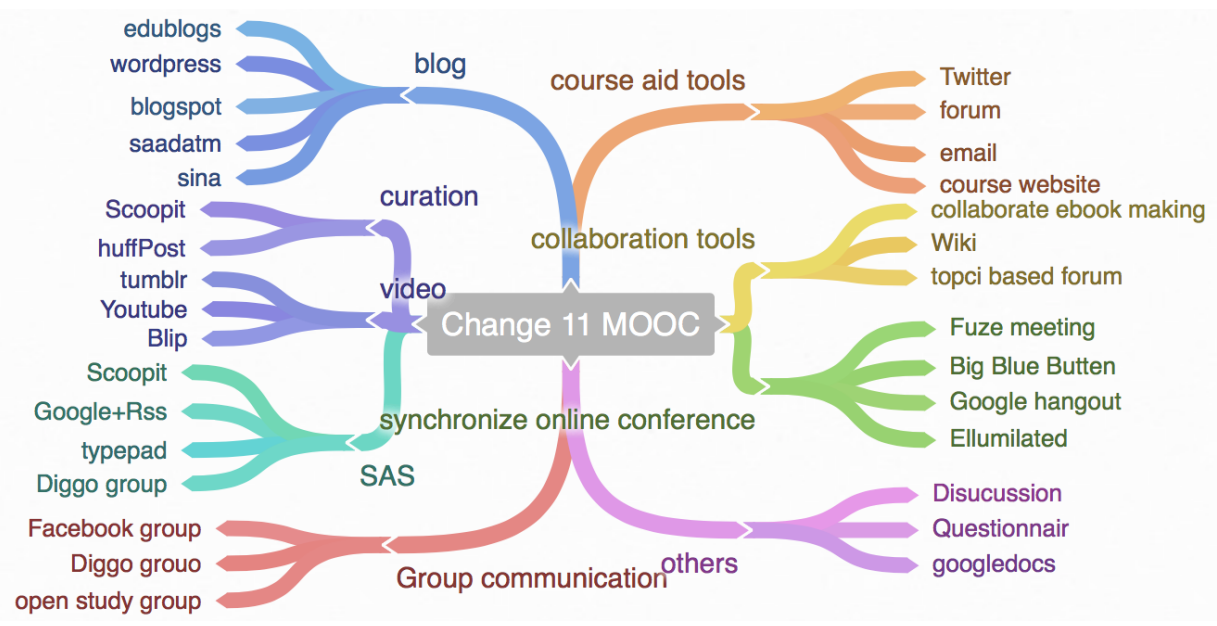

Figure 2. Technology learner used to support their learning in Change 11 MOOC.

Though many other technologies were adopted by some learners, the main technologies used collaboratively during the course were personal blogs, Twitter, and some group communication technologies such as Facebook group and Open Study group. Considering the needs (and challenges) of data accessibility, this study selected interaction traces based on blog, Twitter, a Facebook group, and synchronized audio/video conferences for further analysis.

\section{Participation Categories}

cMOOCs are designed to build a complex information environment for all participants using learner-driven learning artifact creation, and remixing, reflection/summarization, discussion/negotiation, information aggregation, and sharing on course themes (Wang, Chen, \& Anderson, 2014). As mentioned above, learners should have high degree of autonomy (Skrypnyk et al., 2015) and should be self-directed and network directed in this kind of course. If the learners did not make contributions (such as post blog, comments, information sharing, and aggregation on themes) to the course, the course can hardly be described as a cMOOC. This hyper participation and contribution to the content is different from xMOOCs, where the vast majority of content is created and presented by instructors only.

Table 2 lists six categories of the number of people participating in Change 11 MOOC from the first week to the sixth week, including the number of registered, daily newsletter subscribers, number of blog feeds generated, the topic generated and number of participants involved in blog, Twitter and Facebook group interactions. The first three rows were obtained based on the participant data of week 1 to week 6 published by Downes (2011b), and the later three items were retrieved from social network analysis of transcripts in the course. The open and distributed characteristics of blog, Twitter, Facebook group, and the functional design of these technologies preclude our obtaining data related to how many people read these interactions. Thus, the three rows of data are retrieved from the transcript of interaction data left in these spaces by social network analysis.

As Table 2 shows, this course attracted more than 1300 registrations, and almost everybody who registered the course also subscribed to the daily newsletter at the beginning of the course. In these six weeks, the 
number of people registered in the course, subscribing to the daily newsletter, and generating blog posts increased over time. At the sixth week, more than 2000 people had registered in the course, and the cMOOC had attracted worldwide attention. Each week, from 100 to 200 topics were generated by the participants based on the content the facilitators provided.

Table 2

Number of Participants in Different Spaces Each Week

\begin{tabular}{|c|c|c|c|c|c|c|}
\hline & Week 1 & Week 2 & Week 3 & Week 4 & Week 5 & Week 6 \\
\hline Registered number & 1774 & 1892 & 1940 & 2013 & 2079 & 2130 \\
\hline $\begin{array}{l}\text { Daily newsletter } \\
\text { subscribe number }\end{array}$ & 1714 & 1807 & 1832 & 1884 & 1931 & 1972 \\
\hline $\begin{array}{l}\text { Blog feed } \\
\text { recipeients number }\end{array}$ & 192 & 216 & 231 & 241 & 252 & 258 \\
\hline Blog posts number & 138 & 202 & 160 & 156 & 84 & 151 \\
\hline $\begin{array}{l}\text { Twitter posts } \\
\text { number }\end{array}$ & 294 & 246 & 294 & 236 & 215 & 166 \\
\hline $\begin{array}{l}\text { Facebook group } \\
\text { posts number }\end{array}$ & 171 & 121 & 57 & 52 & 32 & 61 \\
\hline
\end{tabular}

Despite the steady increase in registrations, the number of people participating and interacting in the daily newsletter, Twitter, and the Facebook group showed a strong randomness, and did not increase with the increase in registered participants.

Other MOOC researchers have divided learners into different types (Hill, 2013; Milligan et al., 2013), such as active participation, passive participation, and lurking. Milligan and his colleagues (2013) and Hill (2013) added drop-ins as the fourth type for those "who are partially or fully active for their specific learning needs" (Hill, 2013, The Four Student Archetypes section, para. 4). However, cMOOCs are designed within the pedagogy of connectivism which proposes that learning is a network creation. This creates both a challenge and an opportunity for learners to participate in the course, so we divided learners using the lens of connectivism and combined it with a particular course design.

As described in Table 1, there were four categories of interactive behavior.

1. Unconnected floaters: These participants registered in the course thus showing their willingness and intent to participate but did not subscribe to the daily newsletter. They can only receive information of the course through course website as in xMOOCs, and did not likely get the latest information of the course by email or blog post on time. According to our cMOOC pedagogical design, they are labeled as unconnected floaters.

2. Connected lurker: These learners followed the course through the daily email newsletter, but did not make contribution (create new learning artifact or interact with others) to the course. 
Interaction with the content by subscribing to the daily newsletter was the primary (and most often only) connection with the course, though they may have forwarded the email or privately interacted with other participants enrolled or not in the course. However, these lurkers, potentially including the ones having deep interaction with the content by independent study, did not have social interaction with others.

3. Connected participant: A cMOOC uses an interaction-centered design. Connected participants actively engage in the course and share their participation activities. In this course, they not only subscribed to daily newsletter, contributed their blog feeds to the course, and also made blog post and comments on the selected themes and topics they were interested in on the main interaction spaces, such as blog, Twitter, and the Facebook group.

4. Active contributor: These are the participants who not only connect with content actively, but also contribute their knowledge by creating learning artifacts. In this course, they are the one who actively post blogs to express their views and make comments on others' ideas on the themes and topics each week. They are long-standing residents in the course, and can often be found on all main learning spaces supported by different media. This type of learner is rarely seen in other MOOCs.

While analysing the participation pattern of learners in the course, we found that the number of learners in each of the categories above followed a similar pattern to interaction in many online social systems (Nielsen, 2006). More than $93 \%$ of those registered subscribed to the daily email newsfeed, $12 \%$ of them contributed their blog feeds, and between $4.04 \%$ and $10.78 \%$ of them contributed content that was redistributed in the daily newsletter each week during these six weeks. If we change the total number into 100 and use the average ratio in blog based daily newsletter and Twitter, the ratio of four categories of participant is 2 unconnected floaters, 78 connected lurkers, 11 active contributors, and 9 active contributors. This is described as Figure 3 .

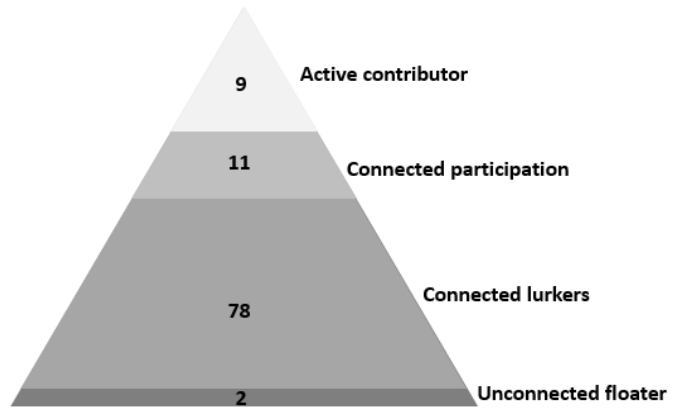

Figure 3. Participant inequality in Change 11 MOOC.

\section{Social Network Structure Formed in Different Spaces}

Connectivism claims that learning is a process of building both inner neural networks, and external conceptual networks and social networks (Siemens, 2005b). At the beginning of the course, the participants were isolated, but as the course proceeded, deeper connection were built among them through these 
interactions. In this cMOOC, learners formed a large social network in the course. The structure of social networks looks slightly different in the blog, Twitter, and Facebook group due to unequal participation in each. Because of the different degrees of openness, ownership, and technical affordances, each technology played a different role in supporting this kind of learning.

Using the blog based interaction in the first week of the course as an example, Figure 4 illustrates the social network layout with the Harel-Koren (HK) fast multi-scale algorithm, which is one of NodeXL's two forcedirected algorithms.

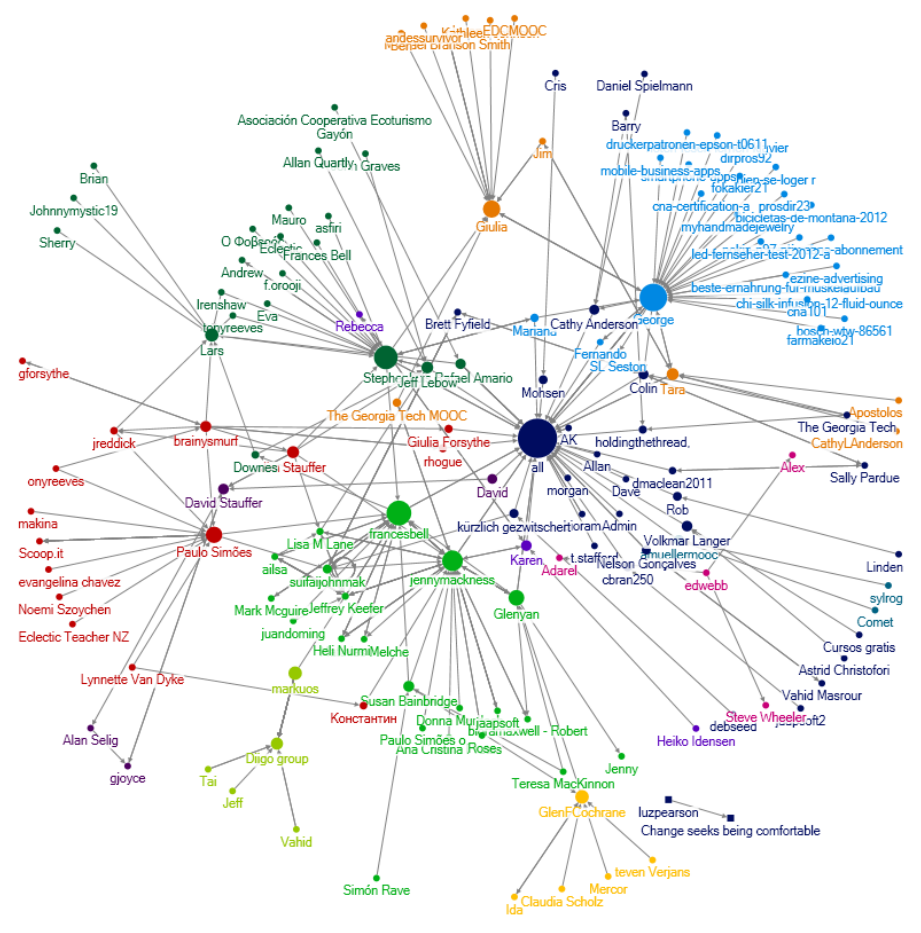

Figure 4. The social network of the first week blog based interaction

Table 3 represents a view of this social network with 309 edges, 143 nodes in the network. That means there are 309 interaction among these 143 nodes. There are five special (particularly central) nodes in the network: all, eduMOOC, The George Tech MOOC, Diggo group, and Soop.it. The node "all" is defined to count how many people submit original blog post to the course. The in-degree node "all" is 33, which is also the maximum in degree of the network, and the edges of "all" is 48 . That means 33 people contributed 48 original blog post to the course. The node "eduMOOC" and "The George Tech MOOC" represents other MOOCs connected within the course, and the node "Scoop it" is a curation technology participants adopted in their learning. The node "Diggo group" represents a group build by some participants to aggregate information. So, 138 participants joined in the blog based social interaction in the first week. The maximum out-degree of this social network is 11. It belongs to the node "jennymackness," who is a learner in the course. The maximum intermediate centrality of this social network is 5397, it belongs to node 
"George," who is one of the facilitator in the course. So, the facilitator played an important communication role among participants in the first week of blog based interaction.

Table 3

The Overall Metrics of Social Networking in the First Week of Blog-Based Interaction

$\begin{array}{cccccc}\text { Nodes } & \text { Edges } & \text { Self-loop } & \begin{array}{c}\text { Maximum } \\ \text { in degree }\end{array} & \begin{array}{c}\text { maximum } \\ \text { out-degree }\end{array} & \begin{array}{c}\text { Maximum intermediate } \\ \text { centrality }\end{array} \\ 143 & 309 & 4 & 33 & 11 & 5397\end{array}$

Social network researchers have noted that "types and patterns of relationships emerge from individual connectivity and that the presence (or absence) of such types and patterns have substantial effects on the network and its constituents" (Mika, 2007, p.27). In order to detect the network structure, we use the Clauset-Newman-Moore algorithm to cluster this social network first and then stratified it. As Figure 5 shows, 13 groups and 6 network structures were formed. The largest group is "all," and most nodes in that group are connected with nodes in other groups. There are five isolated nodes (admin, bioram, Dave, demanclearn11, Morgan) in the network connected with the node "all." The six network structures can be described as star structure (A), network structure (B), self-loop structure (C), triangle structure (D), bridge structure (E), and isolated structure (F). Star structure (A) is the main structure of the network. In this network, groups of George, Guilia, Stephen, Paulo Simões are star structure networks. These nodes are the center of these small networks. Network structure (B) is complicated - there is no center among these nodes and there are many interactions among these nodes; many complicated interactions happened among the nodes. Self-loop structure (C) illustrates those who wrote comments on their own blog post as to provide further information and reflection. Triangle structure (D) is the structure connected with two or three main nodes. Bridge structure (E) is a linear structure; if one of them is not connected, this network cannot reach other nodes. Isolated structure (F) is the one isolated network among two or three nodes. The nodes of these structures did not connect with other groups or nodes.

As Figure 5 illustrates, multi-interaction centers were formed following a high sequence of interaction. The participants in the center not only have a deep connection with other participants in other centers, but are also connected with many participants who were relatively isolated in the course. They acted as the "obligatory points of passage" in Actor Network Theory (Latour, 2005) in this network, because the important information in the network will flow to these centers and be amplified by them. 


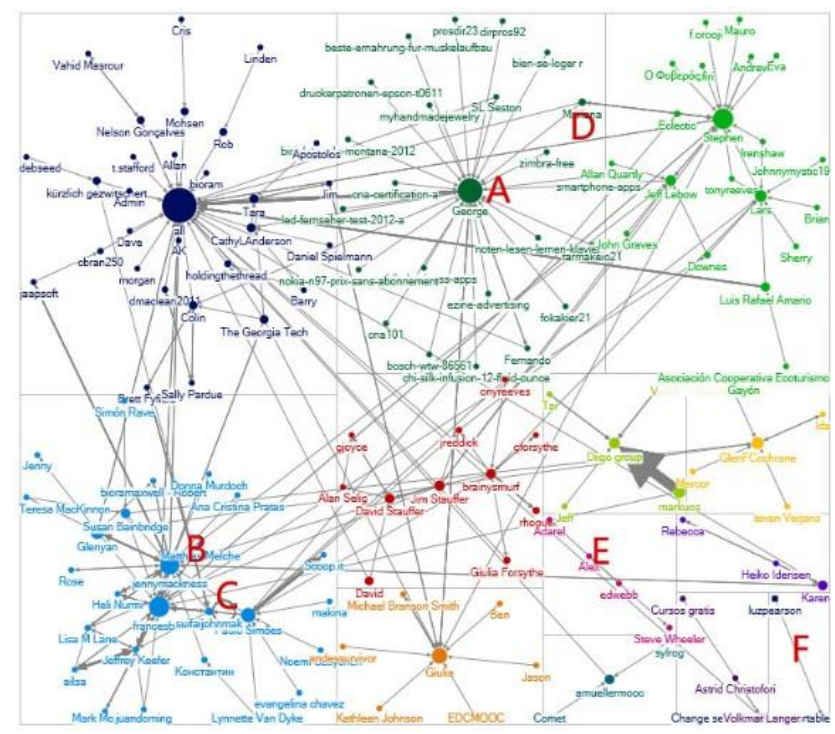

Figure 5. The structure of the social network in the first week from blog based interaction.

\section{Typical Participation Pattern Based on Deep Interactive Topic}

As Downes (2007) argued, learners should be active participants in content generation and interaction to maximize their own learning. Learners not only interacted with other learners, but also participated in content creation in this course. Table 4 lists the total number of posts and interactions in the blog, Twitter, and Facebook group in six week. All participants in this course generated 1176 original blog post, 2516 original Twitter post, and 511 original Facebook group posts in the sixth week of the course, and the interaction behavior based on these original posts is two times greater than average number of posts. This may support the claims that cMOOCs is an interactive, emergent, and creation-based course. The average number of interactions on each topic in the blog and Facebook are more than those generated on Twitter; however, the total post and interaction number in Twitter is much higher than the other spaces. This is probably because posting a Twitter is much faster and easier than creating a blog post and Facebook message.

Table 4

The Number of Posts and Interactions Generated in Different Spaces Each Week

$\begin{array}{llllllll} & \text { Week 1 } & \text { Week 2 } & \text { Week 3 } & \text { Week 4 } & \text { Week 5 } & \text { Week 6 } & \text { Total } \\ \text { Blog post } & 113 & 158 & 242 & 284 & 158 & 221 & 1176 \\ \text { Blog interaction } & 311 & 476 & 388 & 401 & 179 & 667 & 2422 \\ \begin{array}{l}\text { Twitter post } \\ \begin{array}{l}\text { Twitter } \\ \text { interaction }\end{array}\end{array} & 517 & 559 & 512 & 423 & 283 & 222 & 2516 \\ & 713 & 511 & 743 & 604 & 445 & 369 & 3385\end{array}$




$\begin{array}{lccccccc}\begin{array}{l}\text { Facebook group } \\ \text { post }\end{array} & 228 & 99 & 55 & 43 & 17 & 69 & 511 \\ \begin{array}{l}\text { Facebook group } \\ \text { interactions }\end{array} & 546 & 291 & 211 & 176 & 49 & 124 & 1397\end{array}$

From Table 4, the number of interactions in each space is almost two times the number of related original post in these spaces. At first glance, the interaction in the course is not heavy. That is because in nearly 50\% of the postings there were no replies posted. We can speculate that this is related to the perception that the content is too simple, to obscure, too easy, or did not create anything new; it was written in other languages than English; or that it overlapped with other content and information in this complex information environment. However, some high quality topics had intensive interaction and debates, during the learning process, and even inspired some new topics. For example, one participant posted a blog "Orienting myself to the Change 11 MOOC" in his blog site. Twenty-one participants made 33 comments on it including 28 deep discussions under the blog, and five pingbacks from Scoop it and other blogs. When tracking the interaction data further, we found that three new topics were generated over the course and one of these generated yet another new topic. Figure 6 presents the name of topic and their relationships. It is a prototype of the conceptual network formed in the course.

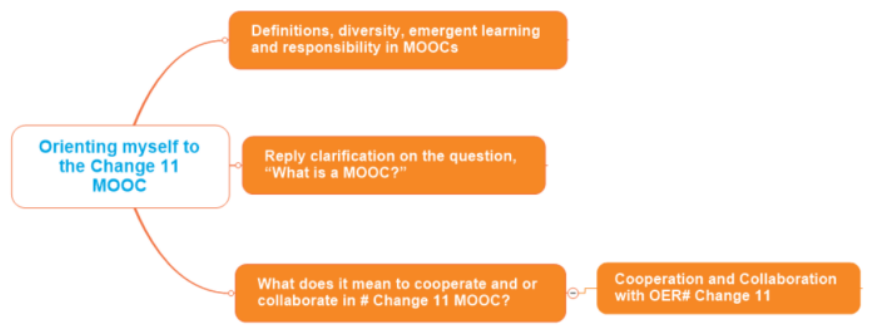

Figure 6. Topic generated base on the "orientation myself in MOOCs" post.

What is more important is that all these topics lead to further discussion in other blog spaces with other participants. The number of comments and pingbacks (a new blog post, in response to the original post) from each topic are listed in Table 5 . 
Table 5

The Interaction Data Based on the Generated Topic

Topic Poster Interaction data

Orienting myself to the

Change 11 MOOC Francesbell

35 comments;5 pingbacks

Definitions, diversity, emergent learning, and responsibility in MOOCs

Jennymackness

20 comments; 4 pingbacks

Reply clarification on the question, "What is a MOOC?”

Jeffrey 7 comments; 2 pingbacks

What does it mean to cooperate and or collaborate in \# Change 11 Suifaijohnmak 8 comments; 5 pingbacks MOOC?

Cooperation and

Collaboration with OER\# Change 11 kürzlich gezwitschert $\quad 1$ comments; 1 pingbacks

Not only was a concept network formed, but also a social network around this topic emerged. Figure 6 and 7 illustrated the topic network and social network formed around this topic through participant's interactions. These two networks based on one generated topic are only a small part of the whole social and concept network of this course. It provides an example of Siemens oft-quoted description of "learning as network creation" (Siemens, 2005b, Abstract section, para. 1).

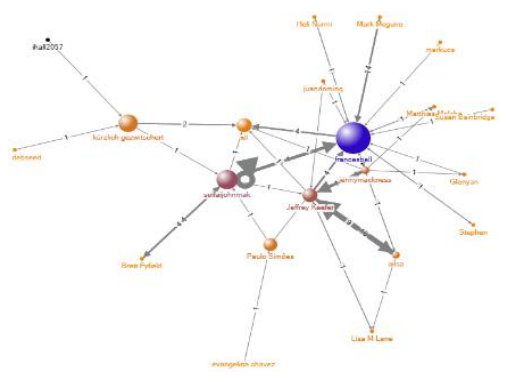

Figure 7. Social network of the topic "orientation myself in the MOOCs." 


\section{Conclusion and Discussion}

This study explored learners' participation in a connectivist learning context from the perspective of the technology adopted by learners, the participation categories that emerged, the social network structure formed, and a typical conceptual network that was formed based on topics in the course. After the analysis of six weeks' interaction transcript in Change 11 MOOC, we get a clearer picture of learners' participation in this kind of learning.

1. A large and diverse technology map was formed in the course. The eight categories of technologies map in this course include all five kinds of affordances of social software tools proposed by McLoughlin and Lee (2007): connectivity and social rapport, collaborative information discovery and sharing, content creation, knowledge and information aggregation, and content modification. Each technology played a slightly different role in the course based on their main functions, affordances, participant competence, and usage in supporting learning. This supports the idea that "learning occurs in a socio-cultural system in which learners use various tools and multiple forms of interaction to create collective activity, supported by technology affordances" (McLoughlin \& Lee, 2007). Further that "technology is an enabler of new opportunities" (Siemens, 2009, p. 2); each technology can create a different learning space for the learner. In this course, students were given freedom of choice to select different kinds of technologies to support their learning according to their individual and collective interaction preferences, technology and bandwidth availability, and technology affordances. Everyone can build their own learning spaces and group learning spaces in this kind of course, which also makes it is possible to connect with different learners in and outside of the course. Through the contribution and participation of every active learner, a complex technology environment, for both individuals and collective networks, was formed through the course. As Weiser (1991) stated that " $(t) h e$ most profound technologies are those that disappear" (p. 94). We argue that the best technology in learning is the one that has disappeared in learning. It follows that we should, and can, allow and support student trialing, use and adoption of the technology they find most useful for their learning and thus build their own the personal learning environments. Through analysis of this data, we found that there are differences among the number of participant in the use of various technologies. The largest number of learners were involved in Twitter-based posts and interactions. Less were involved in blog-based social interaction; 270 of them registered in the Facebook group and 40-60 joined in the online video conference. This supports the idea that we proposed in the Connectivist Interaction and Engagement (CIE) framework that: the higher the cognitive engagement required, the less participants will participate (Wang, Chen, \& Anderson, 2014). The limit of 140 words of Twitter, makes it is easy and fast to edit and does not require higher levels of cognitive engagement - thus participants can easily participate. The aggregation of blogs distributed using the daily newsletter was the main learning resources generated in the course for learners, and 92\% register subscribed to it. However, active participation in this kind of blog-based interaction requires deeper cognitive engagement compared with interaction in other spaces. Perhaps because the blog can express more ideas in one post than Twitter, so the number of average interactions arising from one blog post is more than those from a single Twitter post. The Facebook group established by a participant attracted a much smaller learner group, so the interaction in it was also less than other technologies. 
2. We divided learners' participation in the course into four categories, according to their participation patterns in the course. These are unconnected floaters, connected lurker, connected participant, and active contributor. The ratio of these four types of learners are 2 unconnected floaters, 78 connected lurker, 11 connected participant, and 9 active contributor. Nielsen (2006) proposed "the 90-9-1 rule for participation inequality in social media and online communities," which means that "in most online communities, 90\% of users are lurkers who never contribute, $9 \%$ of users contribute a little, and $1 \%$ of users account for almost all the action" (Nielsen, 2006, para. 4). Clow (2013) also proposed a funnel of participation in xMOOCs - the number of participant decreases from awareness, to registration, to activity, and progress. As illustrated in Figure 4, these two principals were supported in the Change 11 MOOC. However, the active contributors in Change $11 \mathrm{MOOC}$ is much higher than the $1 \%$ active participant in most online communities. Lee (2012) found that students read many peer's postings but selectively responded only according to their interest. Though learners' participation in Change 11 MOOC still supported Lee's conclusions, the frequency and number of posts and responses of others post is much higher than in xMOOCs. The design pedagogy likely influenced this difference. In this sense, Change 11 MOOC was a successful course that had more active participation than that observed in more general, less focused, and informal online communities.

Although we do see a participation model that is roughly similar to other MOOCs and online communities, these four categories have different meaning than other studies. The "active participant" in other MOOCs are those who make active contribution in the course discussion forum is just a part of "connected participant" in a cMOOC. It is hard to find the active contributor of other xMOOCs and online courses as we defined in this study. This can be supported by the empirical research that use the interaction analysis model for social construction of knowledge developed by Guanawardena, Lowe, Constance, \& Anderson (1997), that divided the interaction into five levels (Sharing/comparing of information; discovery and exploration of dissonance or inconsistency among ideas, concepts or statements; negotiation of meaning/ co-construction of knowledge; testing and modification of proposed synthesis or co-construction; agreement statement application of newly constructed meaning). They found that it is hard for students to reach the fourth and fifth levels, thus, more research should be done by comparative study of these different categories of participants among cMOOCs, xMOOCs, and other online learning communities.

3. This study identified six basic structures of social networking formed during learning and found out that participants played a different role compared to traditional courses or xMOOCs. Indeed some participants played more active, and arguably more important, roles than the facilitators. The center of these emergent social networks was always changing as the course moved along. It is interesting to find that facilitators' central position in the network is not obvious - many participants played an equally (sometimes more) important role than facilitators. In the selected three spaces, we found that facilitators were more active in Twitter than the blog, and it is difficult to even identity their presence in the Facebook group. The ones who make high quality posting and 
important information (based upon number of responses or comments) or those that join in deep interaction with more than a single topic can play key roles in the network.

The complete social network formed in the course was complex, not only for its structure, but also the different learning behaviors behind the network and the topic. Social network analysis is a quantitative research method, and behind each interaction there are various motivations, interaction behaviors, methods, styles, and purposes. The social network analysis should be combined with learning behavior analysis and with learning technology analysis in this type of learning. The different interaction behaviors may represent different interaction depth and intent of learners in the course. The technology used, in part, determines the interaction behavior that learners can make in their learning, thus, we need deeper analysis and understanding through combining social network analysis, learning behavior analysis, supporting technologies, and qualitative intent and perception analysis together to gain a deeper understand about learners' participation in this kind of learning.

4. This study explored typical participation patterns based on interactive topics with an example of blog-based interaction. The topic generation process, the interaction around on it, and the social network formed around this topic are each examined. More than 4000 posts were generated in the three main spaces of the course and each topic had the potential to inspire interaction amongst participants. Though there are some topics that received no replies, we argue that this does not mean they did not have interaction potential. For example, we found a Spanish participant published a post in English and nobody replied to it. However, when he published the same text in his blog in Spanish, 12 replies were made. So, with a change in audience or context, the result may be different. This is the value of connectivism. Every topic and every participant has the potential to connect with participants with different background together, the increased diversity of the topic and participants adds to the power and utility of the network.

Considering the cognitive engagement of learners, there are four levels of interaction from operation, wayfinding, sense-making, to innovation in CIE (Wang, Chen, \& Anderson, 2014). Though there are more active contributors in this cMOOC than other communities and in most xMOOCs. When considering the quality of their posts, perhaps only a few of these reach the innovation level, because learners may make contribution at different levels according to their learning objectives, interests, and learning abilities. When analysing the technologies learners adopted to support their connectivist learning and the participation patterns, we found that different technologies work at different levels of interaction to support the learning. For example, Twitter was mainly used in the work at the wayfinding level and blog worked more at the sense-making and innovation levels. The deepest interaction happened in the blog space followed by the Facebook group and Twitter. It follows that we need more research to more clearly understand learners' participation with the CIE framework to gain a deep understand on learners' participation. This study also reports on a typical concept network and social network formed around a topic. In the future, we will analyse these networks forming and changing processes in each space over a limited number of weeks. It will provide us more generalized insights into learners' participation in the connectivist learning process. 
In order to get a clearer picture of how learners participate in connectivist learning, this paper analyses learners' social interaction traces retrieved from different perspectives from network building and formulation. We also examined learners' participation by various technologies (technology network) by the social network of a space and around topic and topic generation process. Each of these approaches can be analysed and compared from both quantitative and qualitative perspectives (Skrypnyk et al., 2015; Bozkurt et al., 2016). This will be a future focus of our study. The limitation of this study is that we only analyse the data left in the typical spaces that are easily and publically accessed in the internet. There's no doubt that other interactions occurred in other closed groups, private communication, or were not recorded on the internet. Thus, in the future, we need to use multiple forms of public and private research to understand learner behaviours and approaches in this much less structured learning context.

\section{Ethical Considerations}

The authors state that there was no conflict of interest involved in this study. We obtained permission from one of the course facilitators- George Siemens - to use the data in the research. When participants registered into the Change $11 \mathrm{MOOC}$, they signed an agreement that permitted the use of their data for research purposes (http://change.mooc.ca/privacy.htm). All of data can be accessed without passwords in the internet.

\section{Acknowledgements}

We thank Dr. George Siemens for permission to access the data in Change 11 MOOC. Our work is supported by a National Natural Science Foundation of China (L1624020), and the Fundamental Research Funds for the Central Universities in China (2017JDZDo7). 


\section{References}

Arnold, P., Kumar, S., Thillosen, A., \& Ebner, M. (2014) Offering cMOOCs collaboratively: The COER13 experience from the convenor's perspective, In U. Cress, \& C. D. Kloos (Eds.),.Proceedings of the European MOOC Stakeholder Summit 2014 (pp. 184-188). Retrieved from https://www.researchgate.net/profile/Anja Lorenz/publication/263543544 Open Online Cou rses in the context of higher_education an evaluation of a German_cMOOC/links/54941 c560cf2e1b6095f97bc.pdf

Bonsignore, E. M., Dunne, C., Rotman, D., Smith, M., Capone, T., Hansen, D. L., \& Shneiderman, B. (2009, August). First steps to NetViz Nirvana: Evaluating social network analysis with NodeXL. In CSE 'o9: International Conference on Computational Science and Engineering(Canada),Vancouver (pp. 332-339). Los Alamitos: IEEE Computer Society Press.

Bozkurt, A., Honeychurch, S., Caines, A., Maha, B., Koutropoulos, A., \& Cormier, D. (2016). Community tracking in a cMOOC and nomadic learner behavior identification on a connectivist rhizomatic learning network. Turkish Online Journal of Distance Education, 17(4). Retrieved from http://dergipark.ulakbim.gov.tr/tojde/article/view/5000204512.

Clow, D. (2013, April). MOOCs and the funnel of participation. In Proceedings of the Third International Conference on Learning Analytics and Knowledge (pp. 185-189) Leuven, Belgium; New York: ACM.

Crosslin, M., \& Dellinger, J. (2015). Lessons learned while designing and implementing a multiple pathways XMOOC + cMOOC. In D. Rutledge \& D. Slykhuis (Eds.), Proceedings of Society for Information Technology \& Teacher Education International Conference 2015 (pp. 250-255). Chesapeake, VA: Association for the Advancement of Computing in Education (AACE).

Daniel, J. (2012). Making sense of MOOCs: Musings in a maze of myth, paradox and possibility. Journal of Interactive Media in Education, 3. Retrieved from http://wwwjime.open.ac.uk/jime/article/viewArticle/2012-18/html

Downes, S. (2007). Learning networks in practice. Emerging Technologies for Learning, 2, 19-27. Retrieved from http://ijklo.org/Volume3/IJKLOv3po29-044Downes.pdf

Downes, S. (2011a).Moving beyond self-directed learning: Network-directed learning [Blog post]. Retrieved from http://www.downes.ca/post/55361

Downes, S (2011b). MOOC statistics thus far [Blog post]. Retrieved from http://halfanhour.blogspot.com/2011/11/mooc-statistics-thus-far.html

Downes, S. (2012a). Massively open online courses are 'here to stay'[Blog post]. Retrieved from http://www.downes.ca/post/58676 
Downes, S. (2012b). Connectivism and connective knowledge: Essays on meaning and learning networks [PDF]. National Research Council Canada. Retrieved from http://www. downes. ca/files/books/Connective Knowledge-19May2012. Pdf

Fidalgo-Blanco, Á., Sein-Echaluce, M. L., \& García-Peñalvo, F. J. (2016). From massive access to cooperation: lessons learned and proven results of a hybrid xMOOC/cMOOC pedagogical approach to MOOCs. International Journal of Educational Technology in Higher Education, 13(1), 1-13.

Fini, A. (2009). The technological dimension of a massive open online course: The case of the CCKo8 course tools. The International Review of Research in Open and Distance Learning, 1O(5). Retrieved from http://www.irrodl.org/index.php/irrodl/article/viewArticle/643/1402Continued

Fournier, H., Kop, R., \& Durand, G. (2014). Challenges to research in MOOCs. MERLOT Journal of Online Learning and Teaching, 10(1), 1-15.

Guanawardena, C. N., Lowe, X., Constance, A., \& Anderson, T. (1997). Analysis of a global debate and the development of an interaction analysis model for examining social construction of knowledge in computer conferencing. Journal of Educational Computing Research, 17(4), 397-431.

Hew, K. F. (2016). Promoting engagement in online courses: What strategies can we learn from three highly rated MOOCS. British Journal of Educational Technology 47(2), 320-341.

Hill, P. (2013). The four student archetypes emerging in MOOCs [Blog post]. Retrieved from http://mfeldstein.com/the-four-student-archetypes-emerging-in-moocs/

Kop, R. (2010, June). The design and development of a personal learning environment: Researching the learning experience. Paper H4 32 presented at the European Distance and E-learning Network Annual Conference 2010, Valencia, Spain.

Kop, R. (2011). The challenges to connectivist learning on open online networks: Learning experiences during a massive open online course. The International Review of Research in Open and Distance Learning, 12(3), 19-38. Retrieved from http://www.irrodl.org/index.php/irrodl/article/view/882/1689

Latour, B. (2005). Reassembling the social-an introduction to actor-network-theory. Oxford: Oxford University Press.

Lee, J. (2012). Patterns of interaction and participation in a large online course: Strategies for fostering sustainable discussion. Educational Technology \& Society, 15(1), 260-272.

Levy, D. (2011). Lessons learned from participating in a connectivist massive online open course (MOOC). In Y. Eshet-Alkalai, A. Caspi, S. Eden, N. Geri, \& Y. Yair, (Eds.), Proceedings of the Chais conference on instructional technologies research 2011: Learning in the technological era (pp. 
31-36). The Open University of Israel, Raanana. Retrieved from

http://www.openu.ac.il/research center/chais2011/download/f-levyd-94 eng.pdf

Li, S., Tang, Q., \& Zhang, Y. (2016). A case study on learning difficulties and corresponding supports for learning in cMOOCs. Canadian Journal of Learning and Technology, 42(2). Retrieved from https://eric.ed.gov/?id=EJ1100651

Mackness, J., Mak, S., \& Williams, R. (2010). The ideals and reality of participating in a MOOC. In Proceedings of the 7th International Conference on Networked Learning 2010 (pp. 266-275). University of Lancaster, Lancaster.

McLoughlin, C. \& Lee, M. J. W. (2007). Social software and participatory learning: Pedagogical choices with technology affordances in the Web 2.0 era. In ICT: Providing choices for learners and learning. Proceedings ascilite Singapore 2007. Retrieved from http://www.ascilite.org.au/conferences/singaporeo7/procs/mcloughlin.pdf

Merceron, A., Blikstein, P., \& Siemens, G. (2016). Learning analytics: From big data to meaningful data. Journal of Learning Analytics, 2(3), 4-8.

Mika, P. (2007). Ontologies are us: A unified model of social networks and semantics. Web Semantics: science, Services and Agents on the World Wide Web, 5(1), 5-15.

Milligan, C., Littlejohn, A., \& Margaryan, A. (2013). Patterns of engagement in connectivist MOOCs. Journal of Online Learning \& Teaching, 9(2), 149-159.

Nielsen, J. (2006). Participation inequality: Encouraging more users to contribute [Blog post]. Retrieved from http://www.nngroup.com/articles/participation-inequality

Ostashewski, N., Howell, J., \& Dron, J. (2016). Crowdsourcing MOOC interactions: Using a social media site cMOOC to engage students in university course activities [Blog post]. Retrieved from http://oasis.col.org/bitstream/handle/11599/2528/PDF?sequence=4\&isAllowed =y

Riel, J. \& Lawless, K. A. (2017). Developments in MOOC technologies and participation since 2012: Changes since "The year of the MOOC.” In M. Khosrow-Pour (Ed.), Encyclopedia of information science and technology (4th ed.), Hershey, PA: IGI Global, Forthcoming.

Rodriguez, C. O. (2013). Two distinct course formats in the delivery of connectivist MOOCs. Turkish Online Journal of Distance Education, 14(2), 66-80.

Saadatmand, M., \& Kumpulainen, K. (2014). Participants' perceptions of learning and networking in connectivist MOOCs. MERLOT Journal of Online Learning and Teaching, 1O(1), 16-30.

Siemens, G. (2005a). Connectivism: A learning theory for the digital age. International Journal of Instructional Technology and Distance Learning, 2(1), 3-10. 
Siemens, G. (2005b). Connectivism: Learning as network-creation [Blog post]. Retrieved from http://www.elearnspace.org/Articles/networks.htm

Siemens, G. (2009). What Is Connectivism [Google docs]. Retrieved from https://docs.google.com/document/d/14pKVPo ILdPty6MGMJW8eQVEY1zibZoRpQ2CocePIgc Ledit?pli=1

Siemens, G. (2011a). This will be fun: Mother of all MOOCs [Blog post]. Retrieved from http://www.elearnspace.org/blog/2011/05/19/this-will-be-fun-mother-of-all-moocs/

Siemens, G. (2011b). Networked-directed learning [Blog post]. Retrieved from https://wiki.p2pfoundation.net/index.php?title=Networked-Directed Learning\&oldid=49706

Siemens, G. (2011c). Orientation: Sensemaking and wayfinding in complex distributed online information environments (Doctoral dissertation). University of Aberdeen, Aberdeen.

Siemens, G. (2012). MOOCs are really a platform [Blog post]. eLearnspace. Retrieved from http://www.elearnspace.org/blog/2012/07/25/moocs-are-really-a-platform/

Siemens, G. (2013). Massive open online courses: Innovation in education? [Blog post]. Retrieved from https://oerknowledgecloud.org/sites/oerknowledgecloud.org/files/pub_PS_OER-IRP_CH1.pdf

Siemens, G. (2014). Multiple pathways: Blending xMOOCs \& cMOOCs [Blog post]. Retrieved from http://www.elearnspace.org/blog/2014/05/06/multiple-pathways-blending-xmoocs-cmoocs/

Skrypnyk, O., Joksimović, S. K., Kovanović, V., Gašević, D., \& Dawson, S. (2015). Roles of course facilitators, learners, and technology in the flow of information of a cMOOC. The International Review of Research in Open and Distributed Learning, 16(3). Retrieved from http://www.irrodl.org/index.php/irrodl/article/view/2170/3347

Smith, B., \& Eng M. (2013, August). MOOCs: A learning journey. In International Conference on Hybrid Learning and Continuing Education (pp. 244-255). Heidelberg, Berlin: Springer. Retrieved from https://link.springer.com/chapter/10.1007/978-3-642-39750-9 23\#citeas.

Wang, Z. J., Chen L., \& Zhen Q., H. (2014). The development track of MOOCs and three forms of practice. China Educational Technology, 7, 25-33.

Wang, Z. J., Chen L., \& Anderson T. (2014). A Framework for interaction and cognitive engagement in connectivist learning contexts. The International Review of Research in Open and Distance Learning, 15(2):121-141. Retrieved from http://www.irrodl.org/index.php/irrodl/article/view/1709/2838

Wang, Z. J., \& Chen L. (2015). Theory framework building of instructional interaction in connectivist learning context. Open Education Research, 21(5), 25-34. 
Wang, Z. J., Anderson, T., Chen, L., \& Barbera, E. (2017), Interaction pattern analysis in cMOOCs based on the connectivist interaction and engagement framework. British Journal of Educational Technology, 48(2), 683-699. Retrieved from http://onlinelibrary.wiley.com/doi/10.1111/bjet.12433/abstract

Weiser, M. (1991). The computer for the 21st century. Scientific American, 265(3), 94-104.

\section{Athabasca} University

$$
\text { (c) (†) }
$$

